\title{
Germ cell tumours of childhood: a review of 137 cases
}

\author{
HENRY B MARSDEN, JILLIAN M BIRCH, RICHARD SWINDELL \\ From the Department of Epidemiology and Social Research, Children's Tumour Registry, University of \\ Manchester, and the Department of Medical Statistics, Christie Hospital and Holt Radium Institute, \\ Withington, Manchester
}

SUMMARY One hundred and thirty-seven germ cell tumours occurring in 134 children included in the Manchester University Children's Tumour Registry over a 25-year period have been studied. The incidence and sites of these tumours as seen in a comprehensive population-based registry are presented and the relation between the primary site and histological type is assessed. There were 48 deaths in this series of which 34 were directly due to the tumour. The cause of death in the other 14 cases is given. The behaviour of the germ cell tumours was closely related to the presence of yolk sac elements.

Teratomas and yolk sac tumours comprise a relatively small but important group in the field of paediatric oncology. The majority of these neoplasms with the exception of sacrococcygeal teratomas and certain testicular tumours are more commonly seen outside the paediatric age range. ${ }^{1}$ The variable histological features may give rise to difficulty in classification and prediction of clinical behaviour. With these aspects in mind, the experience of the Manchester University Children's Tumour Registry has been reviewed.

\section{Patients and methods}

The Manchester University Children's Tumour Registry (MCTR) which is population-based is described in detail elsewhere. ${ }^{2}$ All children living in the North Western Regional Health Authority area (Manchester Regional Hospital Board area before 1974) at the time of diagnosis of their tumour are included. The region has a child population (0-14 yr) of approximately one million. It has been estimated that ascertainment as regards malignant tumours is 95-98\% complete. ${ }^{3}$

During the period 1954-78 inclusive, 92 girls and 42 boys with germ cell tumours, three of whom had double primaries, were registered and slides from all cases were available for study. The histological features were classified as follows:

1 Benign teratoma being composed of a mixture of differentiated or mature tissues.

Accepted for publication 21 January 1981
2 Malignant teratoma including embryonal carcinoma, where hyperchromatic and undifferentiated cells, sometimes with an adenocarcinomatous arrangement, are present in a teratoma. The possibility that these represent yolk sac elements has been raised, ${ }^{4}$ but in the absence of any other supporting features it is difficult to be certain that this is indeed the case.

3 Teratoma, uncertain whether benign or malignant, where undifferentiated tissues usually of neural origin are present.

4 Germinoma, showing a uniform arrangement of large cells, as seen in the seminoma or dysgerminoma.

5 Yolk sac tumour or archenteronoma (originating from the archenteron or primitive gut), having loose vitelline tissue, more solid areas, and papillary arrangement of hobnail cells, sometimes showing the perivascular mantles of the endodermal sinus pattern.

6 Choriocarcinoma with syncytial and trophoblastic cells.

7 Mixed tumours, showing features of more than one of the above groups.

Treatment of the 137 tumours was by surgery alone in 79 , radiotherapy alone in four, surgery and radiotherapy in 21 with additional chemotherapy in 14. Chemotherapy alone was given in one case; in combination with radiotherapy in two and with surgery in 10. There was no treatment in six cases.

Twenty patients had congenital abnormalities: nine involving the central nervous system; four of the genitourinary tract; four of the alimentary tract and three miscellaneous. These abnormalities are discussed in detail elsewhere (Birch, Marsden, Swindell, 
in preparation).

During the'period covered by the present survey five sex-cord mesenchymal tumours were included in the MCTR. These consisted of three granulosa-theca cell tumours, one Sertoli-Leydig cell tumour (arrhenoblastoma) and one Leydig cell tumour of the testis. These tumours are not considered further, but are noted to give an overall picture of the relative incidence of germ cell and sex-cord mesenchymal tumours in childhood, based on a comprehensive population-based survey. There were no cases of gonadoblastoma in the series and, being a retrospective study, the position regarding chromosomal abnormalities is not known.

\section{Results}

\section{ANATOMICAL DISTRIBUTION}

The most frequent site was the ovary $(33 \%)$, followed by the sacrococcygeal region $(23 \%)$, testis $(18 \%)$ and the intracranial region $(9 \%)$. In addition, there were 23 tumours at other sites as shown in Table 1.

\section{INCIDENCE OF HISTOLOGICAL TYPES}

This is shown in Table 2. The majority of tumours (125) were pure, but 12 showed mixed features. The germinoma with choriocarcinoma had an additional malignant teratomatous component, which is not shown in the Table, and areas of benign teratoma were also present in the yolk sac tumour with

Table 1 Distribution of germ cell tumours by primary site

\begin{tabular}{ll}
\hline Site & No of germ cell tumours \\
\hline Ovary & 45 \\
Sacrococcygeal region & 31 \\
Testis & 25 \\
Intracranial region & 13 \\
Abdomen and retroperitoneum & 6 \\
Mediastinum, heart, lung & 5 \\
Pharynx, neck, thyroid & 3 \\
Female genital tract & 3 \\
Spinal cord, meninges & 3 \\
Bladder, prostate & 2 \\
Soft tissues occipital region & 1 \\
\hline
\end{tabular}

germinoma as a second histological feature. Two of the ovarian germinomas were bilateral with identical histological features in both ovaries, and being of simultaneous onset are not considered as separate primaries for the purposes of this paper. However, the 75 benign teratomas include double neoplasms in three of the cases: two cases of tumours occurring in both ovaries and in one case the first tumour was ovarian and the second was in the lung. The time interval $(3,9$ and 1 year respectively) between the development of the lesions, the difference in site, and the benign histological appearances in both first and second neoplasms indicate that the latter should not be regarded as metastases.

\section{PRIMARY SITE AND HISTOLOGICAL TYPE}

The predorninant histological features for the main anatomical sites are shown in Table 3. Germinoma was encountered in the ovary and intracranial region. Yolk sac features were prominent in testicular neoplasms, but were also encountered at most of the other sites. Benign teratoma was seen most frequently in the ovary and sacrococcygeal regions, although nearly half of the testicular tumours were of this type.

The 12 neoplasms with mixed histological features include teratomas with a yolk sac component, of which four were in the sacrococcygeal region, two in the ovary and one each in the testis and intracranial region. Germinoma was also present in the latter tumour and was seen in combination with teratoma in three other intracranial neoplasms. The ovarian tumour which showed germinoma, teratoma, and choriocarcinoma has already been referred to above.

The frequency of each of the various tissues found in pure teratomas and the teratomatous component of mixed tumours was assessed and is shown in Table 4. The most common mature tissues were central nervous system, glandular and skin, and the most common embryonal tissue was neural.

AGE AT PRESENTATION

Of the 20 purely benign sacrococcygeal tumours 17

Table 2 Histological types of germ cell tumours

\begin{tabular}{|c|c|c|c|c|c|}
\hline \multirow{2}{*}{$\begin{array}{l}\text { Secondary histological } \\
\text { type }\end{array}$} & \multicolumn{5}{|c|}{ Predominant histological type } \\
\hline & Germinoma & Yolk sac tumour & Benign teratoma & Malignant teratoma & Teratoma uncertain \\
\hline No second type & 14 & 30 & 75 & 4 & 2 \\
\hline Germinoma & - & $1^{*}$ & 0 & 2 & 0 \\
\hline Yolk sac tumour & 0 & - & 1 & 1 & 1 \\
\hline Benign teratoma & 0 & 2 & - & 0 & 0 \\
\hline Malignant teratoma & 0 & 2 & 0 & - & 0 \\
\hline Teratoma uncertain & 1 & 0 & $\mathbf{0}$ & 0 & - \\
\hline Choriocarcinoma & $1 *$ & $\mathbf{0}$ & 0 & 0 & 0 \\
\hline Totals & 16 & 35 & 76 & 7 & 3 \\
\hline
\end{tabular}

* Teratomatous component in addition. 
Table 3 Distribution by primary site of predominant histological type

\begin{tabular}{|c|c|c|c|c|c|c|}
\hline & Ovary & Testis & Sacrococcygeal & Intracranial & Other & Total \\
\hline Germinoma & 9 & $\mathbf{0}$ & $\mathbf{0}$ & 7 & $\mathbf{0}$ & 16 \\
\hline Yolk sac tumour & 6 & 13 & 8 & 2 & 6 & 35 \\
\hline Benign teratoma & 25 & 12 & $22^{*}$ & 1 & 16 & 76 \\
\hline $\begin{array}{l}\text { Malignant teratoma/embryonal } \\
\text { carcinoma }\end{array}$ & 2 & 0 & $1^{*}$ & 3 & 1 & 7 \\
\hline $\begin{array}{l}\text { Teratoma, uncertain whether benign } \\
\text { or malignant }\end{array}$ & $3^{*}$ & 0 & 0 & 0 & 0 & 3 \\
\hline Total & 45 & 25 & 31 & 13 & 23 & 137 \\
\hline
\end{tabular}

* Minor yolk sac component in one case.

Table 4 Frequency of occurrence of tissues in teratomas

\begin{tabular}{ll}
\hline Embryonic tissues & Frequency $(\%$ total $)$ \\
\hline Neural & $14 \cdot 9$ \\
Mesenchyme & $11 \cdot 5$ \\
Cartilage & $9 \cdot 2$ \\
Epithelium & $6 \cdot 9$ \\
Renal & $2 \cdot 3$ \\
Mature tissues & \\
Central nervous system & $67 \cdot 8$ \\
Glandular & $72 \cdot 4$ \\
Skin & $63 \cdot 2$ \\
Respiratory & $55 \cdot 2$ \\
Alimentary tract mucosa & $28 \cdot 7$ \\
Muscle & $58 \cdot 6$ \\
Fat & $57 \cdot 5$ \\
Cartilage & $46 \cdot 0$ \\
Bone & $28 \cdot 7$ \\
Lymphoid & $37 \cdot 9$ \\
Other & $67 \cdot 8$ \\
\hline
\end{tabular}

were diagnosed at birth. The remaining three were surgically removed at 2,5 and 15 months of age, although in two of these cases symptoms were noted during the neonatal period. In contrast all but two of the 10 sacrococcygeal tumours which showed yolk sac features were diagnosed later than one year of age. The median ages at presentation for ovarian, testicular, and intracranial tumours were $11 \mathrm{yr}, 1 \mathrm{yr}$ and $9 \mathrm{yr}$ respectively, and there were no notable differences with regard to age between histological types at these sites.

\section{PROGNOSIS}

There were 48 fatal cases in this series, 34 being attributed directly to the effects of the tumour. The causes of death in the other patients were as follows:

Complications of treatment 8 (5 intracranial 3 sacrococcygeal)
Malformation

Prematurity

Development of second

tumour
3 (2 sacrococcygeal 1 spinal cord)

2 (1 sacrococcygeal 1 neck)

1 (ovary and lung)
The majority of the complications of treatment were postoperative deaths. The three cases of congenital malformation included a D-trisomy and two patients with spina bifida and hydrocephalus. The case with the second tumour might also be included in the complications of treatment group, carcinoma of the breast developing in a field of previous radiotherapy. The 34 cases in which the tumour was the direct cause of death have been analysed in more detail as shown in Table 5.

\section{GERM CELL TUMOURS (FATAL CASES)}

Yolk sac elements were present in all the sacrococcygeal, testicular, abdominal, and vaginal cases and were seen in 23 of the 34 tumours where the latter was the direct cause of death. They were less important in the intracranial neoplasms, where site was a significant factor. Yolk sac elements were noted in only four of the eight fatal ovarian tumours. Two without yolk sac features were histologically classified as pure teratomas of borderline malignancy,

Table 5 Germ cell tumours (fatal cases)

\begin{tabular}{|c|c|c|c|c|c|}
\hline Site & Number & $\begin{array}{l}\text { Age range (and } \\
\text { mean) (months) }\end{array}$ & Yolk sac elements & $\begin{array}{l}\text { Undifferentiated/malignant } \\
\text { teratoma }\end{array}$ & Other \\
\hline $\begin{array}{l}\text { Sacrococcygeal } \\
\text { Testis }\end{array}$ & 10 & 3- $42 \quad(20)$ & 10 & - & - \\
\hline $\begin{array}{l}\text { Testis } \\
\text { Ovary }\end{array}$ & $\begin{array}{l}4 \\
8\end{array}$ & 7- 22 (15) & 4 & - & $\bar{c}$. \\
\hline $\begin{array}{l}\text { Ovary } \\
\text { Central nervous system }\end{array}$ & 8 & $78-176(144)$ & 4 & 3 & Choriocarcinoma \\
\hline $\begin{array}{l}\text { Central nervous system } \\
\text { Abdominal }\end{array}$ & 7 & $0-135 \quad(72)$ & 2 & 1 & Germinoma \\
\hline Abdominal & 2 & - & 2 & 一 & - \\
\hline Vagina & 1 & - & 1 & - & 二 \\
\hline Heart & 1 & - & - & 一 & Benign teratoma \\
\hline Neck & 1 & 一 & - & - & Benign teratoma \\
\hline Total & 34 & & 23 & & \\
\hline
\end{tabular}


but were clinically malignant and rapidly fatal. In both cases there was multiple peritoneal seeding with massive ascites. No distant metastases were noted. The two benign teratomas caused death by virtue of their size and position.

\section{Conclusion}

The most important numerical group is benign teratoma which accounts for $55 \%$ of the neoplasms in this series. This figure is rather lower than the $78.8 \%$ in a previous survey ${ }^{5}$ based on a study of 85 benign and malignant teratomas in children. The site incidence is also somewhat different, with the greatest number of tumours being gonadal rather than sacrococcygeal. The difference may be the result of a population-based as opposed to a hospitalbased survey. The distribution of tissues found in the present series reflects the patterns described by O'Hare $^{1}$ in his overview of teratomas.

The importance of yolk sac tissue in relation to prognosis in childhood teratomas has previously been stressed $^{67}$ and our study would support this finding. The presence of such elements in intracranial germ cell tumours has been reviewed, ${ }^{8}$ although the relative incidence of this component has not been established. In the present series, two out of 13 intracranial tumours showed yolk sac features.

Sacrococcygeal tumours diagnosed at birth were invariably benign. Presentation of such tumours in older children has sinister implications. However, it would seem from the present series that where symptoms are present at or soon after birth delay in treatment does not result in malignant conversion.

Since completion of this review a male infant with multiple congenital malformations had a histologically benign sacrococcygeal teratoma removed at the age of 10 days. The serum alphafetoprotein (AFP) concentration at that time was normal. Reexcision of tumour at eight months of age was carried out and the tumour regarded as benign, although the serum AFP was raised. A further recurrence excised two months later showed the typical histological features of a yolk-sac tumour.

The presence of yolk sac features is of less prognostic significance in testicular neoplasms than in the ovary, but it has been stated that after excluding yolk sac tumour, choriocarcinoma, and dysgerminoma, there remain metastasising ovarian teratomas. ${ }^{9}$ Two examples of this type of tumour were seen in the present series. Tubules lined by columnar epithelium and possibly of ependymal type were present in these cases. A variety of immature tissues were noted and this may be important in older children - the ages of the cases being 13 and $14 \mathrm{yr}$. Immature neural tissue was noted in the retroperitoneal teratoma of a twomonth-old boy, and mature, partially calcified glial nodules were encountered in the testicular sac six years later. In infancy, the presence of immature tissues does not appear to be such an unfavourable feature as in later childhood.

The relative incidence of yolk sac tumours to malignant teratomas is rather higher in the present series than in a previous study of ovarian teratomata in children collected over 22 years, ${ }^{10}$ and it has been stressed that further study is required to establish the limits of applicability and subclassification of the yolk sac tumours. ${ }^{11}$ The estimation of the serum AFP may help in this connection. It is also possible that incomplete sampling may fail to reveal the presence of yolk sac elements in a particular tumour.

The presence of ependymal-type epithelium with or without other neural tissue and adenocarcinomatous elements which may have a multilayered appearance present particular problems in the absence of PAS positivity, "hobnail" cells, SchillerDuval bodies or loose vitelline tissue. It is suggested that the "ependymal teratoma" may be of yolk sac rather than neural origin. ${ }^{12}$ However, preliminary studies using a peroxidase technique in an attempt to classify the nature of "embryonal carcinoma" have failed to show AFP in the epithelial areas.

In conclusion, it is considered that after excluding tumours of the heart, neck, and intracranial region where "site" played a significant part, assessment of the presence of yolk sac elements was the most important factor in assessing prognosis, although further study is required.

The Manchester Children's Tumour Registry is supported by the Cancer Research Campaign.

\section{References}

${ }^{1}$ O'Hare MJ. Teratomas, neoplasia and differentiation. A biological overview. 1 . The natural history of teratomas. Invest Cell Pathol 1978;1:39-63.

${ }^{2}$ Marsden HB, Steward JK, eds. Tumours in children 2nd ed. Recent results in cancer research Vol 13. Berlin: SpringerVerlag, 1976.

${ }^{3}$ Leck I, Birch JM, Marsden HB, Steward JK. Methods of classifying and ascertaining children's tumours. $\mathrm{Br} J$ Cancer 1976;34:69-82.

4 Beilby JOW. Germ cell and sex cord mesenchymal tumours of the gonads. In: Anthony PP, Woolf N, eds. Recent advances in histopathology. Edinburgh, London, New York: Churchill Livingstone, 1978:259-74.

${ }^{5}$ Grosfield JL, Ballantine TVN, Lowe D, Baehner RL. Benign and malignant teratomas in children: analysis of

\section{.} 西

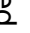
缡 $\infty$ 番 . , . 
88 patients. Surgery 1976;80:297-305.

- Carney JA, Thompson DP, Johnson CL, Lynn HB. Teratomas in children: Clinical and pathologic aspects. J Pediatr Surg 1972;7:271-82.

${ }^{7}$ Gonzalez-Crussi F, Winkler RF, Mirkin DL. Sacrococcygeal teratoma in infants and children. Relationship of histology and prognosis in 40 cases. Arch Pathol Lab Med 1978;102:420-5.

${ }^{8}$ Albrechtsen R, Klee KJ, Møller JC. Primary intracranial germ cell tumours including 5 cases of endodermal sinus tumour. Acta Pathol Microbiol Scand $[A]$ 1972;233:32-5.

${ }^{9}$ Norris HJ, Zirkin HJ, Benson WL. Immature (malignant) teratoma of the ovary. A clinical and pathologic study of 58 cases. Cancer 1976;37:2359-72.
${ }^{10}$ Orr PS, Gibson A, Young DG. Ovarian tumours in childhood. A 27-year review. Br J Surg 1976;63:367-70.

11 Huntington RW Jr, Bullock WK. Endodermal sinus and other yolk sac tumours, a reappraisal. Acta Pathol Microbiol Scand [A] 1972;233:26-31.

12 Huntington RW Jr, Bullock WK. Yolk sac tumours of extragonadal origin. Cancer 1970;25:1368-76.

Requests for reprints to: Dr HB Marsden, Department of Epidemiology and Social Research, Children's Tumour Registry, Christie Hospital, Withington, Manchester M20 9BX, England. 